\title{
Modular automation cabinet for proactive monitoring in ATEX Zone 2
}

\author{
Cristian Nechifor ${ }^{1}$, Claudia Borzea $^{1 *}$, Adrian Stoicescu ${ }^{1}$, Daniel Lale ${ }^{1}$, and Mirela Vasile $^{1}$ \\ ${ }^{1}$ Romanian Research and Development Institute for Gas Turbines COMOTI, 061126 Bucharest
}

\begin{abstract}
The paper presents an automation system dedicated to oil \& gas machinery applications, such as electrical gas compressors. The future aim is to introduce it into the Romanian oil \& gas industry. The system consists of a low size cabinet and its dependencies, which can be used in ATEX Zone 2. The electronic equipment is dimensioned and chosen according to the standards in force, so that the limited current and voltage requirements for methane gas to be met. The key feature is that this system complies with all ATEX standards for Zone 2. Moreover, it can also be a mobile and modular solution if needed, for a versatile and easy use in proactive monitoring of multiple locations across various compressor plants. The design, wireless transmission and possible implementation of this cabinet are presented. Remote data transmission via Wi-Fi and RS-485 communication interfaces between the devices is considered, due to several advantages: mobility, versatility, wide compatibility, environmentally friendly, as well as higher resources efficiency (reducing time and costs).
\end{abstract}

\section{Introduction}

In recent years, due to an increased diversification of research fields and industrial products [1], a versatile modular monitoring equipment for the proactive diagnosis and monitoring of a wide range of industrial equipment $[2,3]$ is becoming more and more useful. Automation systems have started to be modularised in order to be able to monitor a wide range of equipment (such as compressors, electric motors, gas turbines, blowers etc.). A properly designed automation cabinet $[4,5]$ can increase productivity, lowers costs, and ensure processes reliability.

Normally, an industrial automation system is almost strictly designed according to the specifications and needs of the plant it serves. This is detrimental when considering reusing the same automation system or bringing modifying it for a different plant. Regarding the purposes related to monitoring, diagnosis, and/or maintenance, it would be advantageous to use, modular, versatile cabinets that can be easily adapted for the requirements of multiple plants when needed. Ideally is that the cabinets to be easy to install, connect with cabling, so that the installation time not to exceed a few hours, unlike a normal instrumentation which usually takes several days up to weeks, depending on the complexity.

\footnotetext{
*Corresponding author: claudia.borzea@comoti.ro
} 
The requirements for machine and system monitoring and control are increasing, and, in response, so does the interest and research in the design and development of smart innovative solutions for modular explosion proof automation. Modular solutions can be designed in hazardous areas, taking into account all the various aspects of explosion protection and risk assessment [6]. In oil and gas industry, the extraction, transportation, storage, and refining are realised under extremely harsh conditions. In order to comply with the safety standards and regulations [7, 8], explosion proof equipment must be used, and systems not only have to be highly reliable, but also be able to withstand heat, cold, vibrations, shocks and moisture, continuing to operate with minimum maintenance requirements [9].

A portable cabinet has been proposed for applications in non-hazardous areas [10-12]. However, this cabinet [11] cannot be used when dealing with explosive zones, where certified anti-explosive equipment ought to be used. The paper proposes a modular portable cabinet with PLC and inputs/outputs modules and adapters for monitoring a wide range of parameters such as pressures, temperatures, vibrations, torque, speed, level etc. The previously developed portable cabinet has been used intensively by INCDT COMOTI, often being needed for two or more applications at the same time. Therefore, developing more such products for increasing the monitoring systems availability is foreseen. Since COMOTI also deals with gas compression installations and applications for hazardous zones, the present paper addresses the design and future development of a modular portable equipment for monitoring, diagnosis, data acquisition and proactive maintenance.

\section{Modular cabinets intended for hazardous zones}

Explosive atmospheres present in the oil and gas industry usually make the standard equipment incompatible to be used as it is. Even though using explosion-proof versions is the easiest choice, these devices are more expensive, and require more work and time in terms of operation, and maintenance [13]. For designing a control cabinet for hazardous areas, there are two possibilities: either all devices inside must be certified ATEX, with Ex i (intrinsic safety), Ex e (increased protection) or Ex n (non-sparking), either use normal devices placed inside an Ex p pressurized enclosure [14].

A configurable protective Ex p container would allow standard versions of the control, operating and surveillance equipment required on-site to be used in hazardous environments, instead of the solution of having each device with its own explosion protection. Container systems of this type maintain an overpressure inside. However, Ex p enclosures require a bulky system for producing and maintaining the interior pressurization (Fig. 1), making this type of protection unfit for our purposes, due to dimensions, weight, and highly increasing manipulation and transport difficulty. Hence, only the first option can be taken into consideration as a solution, with anti-explosion protection for all devices.


Fig. 1. Pressurised panel enclosure [14] 


\section{System proposed}

The system proposed comprises three main elements, namely:

1. The WMAC (Wireless Monitoring Automation Cabinet) (Fig. 2);

2. Wireless node(s), each able to monitor two analogue input (AI) transducers with unified current signal of 0-20 mA, and two digital input (DI) signals. The transmission is done in 2.4 GHz ISM (Industrial, Scientific, and Medical) radio band.

3. Wi-Fi sensors, which transmit directly to the gateway installed inside the WMAC. (such as vibrations, pressure and/or temperature sensors).

Multiple such wireless nodes can be added into the system, depending on the monitoring requirements, and on the number of transducers placed on the skids, managed by PLC. These WSNs function on batteries, providing an increased mobility. They can be installed on the skids in Zone 2, in the nearest proximity of the points of interest, such as compressor units or electric motors.

\subsection{Portable modular explosion-proof cabinet design and main components}

The WMAC design proposed is presented in Fig. 2 below.

a)

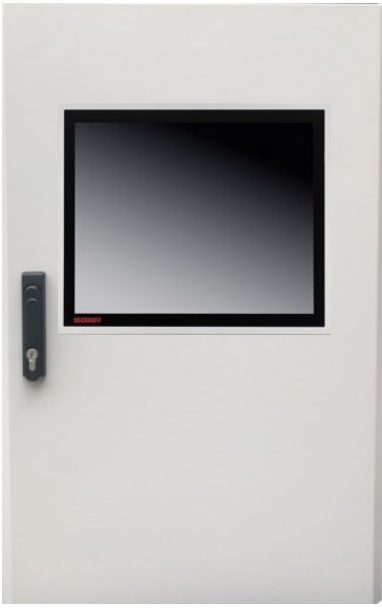

b)

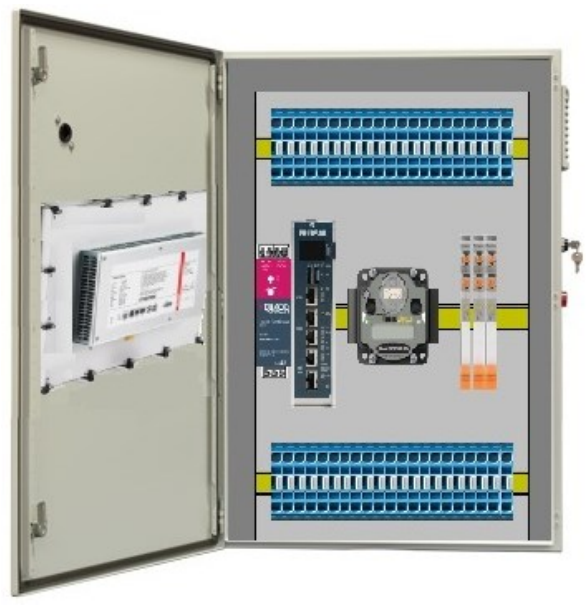

Fig. 2. Conceptual design of an Ex Zone 2 cabinet a) Front door with Panel PC, b) Interior equipment

The main equipment included in the cabinet above is summarised in Table 1 hereinafter.

Table 1. Equipment within the cabinet

\begin{tabular}{|c|c|c|c|}
\hline $\begin{array}{c}\text { Cabinet } \\
\text { components }\end{array}$ & ATEX certification & $\begin{array}{c}\text { Ingress } \\
\text { protection }\end{array}$ & Main specifications \\
\hline Panel PC & AEx ec IIC T4 Gc Ta & IP 65 & 15 ” display \\
\hline Gateway & Ex II 3 G Ex nA II T4 & IP 67 & $\begin{array}{c}\text { Inputs: 4 DI, 2 AI 0-20 mA; } \\
\text { Outputs: 4 DI, 2 DO 0-20 mA, } \\
\text { 2.4 GHz ISM Band }\end{array}$ \\
\hline PLC & Ex II 3 G Ex ec & IP 68 & $\begin{array}{c}2.4 \text { GHz Node 65 mW, Input: } \\
\text { 2 DI, 2 AI, 0-20 mA }\end{array}$ \\
\hline Relays (x3) & II 3G Ex ec nC IIC T4 Gc & $\begin{array}{c}\text { RT III (Relay) } \\
\text { IP20 (Base) }\end{array}$ & $\begin{array}{c}\text { Min./max. switching voltage: } \\
\text { 5 V / 250 V (at 100 mA) }\end{array}$ \\
\hline DC Source* & ATEX II3G & N/A & Output: 24 VDC, 5 A \\
\hline Terminal blocks & Ex i or Ex nA/Ex ec & N/A & $2.5 \mathrm{~mm}$ \\
\hline
\end{tabular}


The PLC and the gateway are connected via a RS-485 interface to the panel PC. In order to provide a proper communication between the devices, the panel PC must be made master, while connecting the CPU (Central Processing Unit) and the gateway as slaves.

WMAC equipment is ideal for the monitoring of certain machineries situated in hazardous zones, covering all the requirements for this purpose. The wireless nodes can be installed even in Zone 0, the device being certified as Ex II 1GD Ex ia IIC T4. Therefore, we have category IIC - industrial equipment group, $1 \mathrm{G}$ - can be used in gaseous Zone 0 , where ignitable concentrations of flammable gases or vapours are present continuously or during long periods of time. Table 2 sums up the power consumption of the devices within WMAC.

Table 2. Power consumption of the devices within the cabinet

\begin{tabular}{|c|c|c|c|}
\hline Equipment & Supply Voltage [V] & Max. current [A] & Power [W] \\
\hline Panel PC & 24 VDC & 1.46 & 35 \\
\hline Gateway & 24 VDC & 0.41 & 10 \\
\hline PLC & 24 VDC & 0.83 & 20 \\
\hline Relays (x3) & 24 VDC & 0.3 & 9 \\
\hline DC Source* & 230 VCA & $0.52(\max )$ & $5 \mathrm{~W}+120 \mathrm{~W}(\max )$ \\
\hline \multicolumn{2}{|r|}{ TOTAL } & 3 A (DC) & $\mathbf{7 4} \mathbf{~ W}$ \\
\hline
\end{tabular}

*The maximum power of the DC source is $120 \mathrm{~W}$, but it will generate only $74 \mathrm{~W}$, where $5 \mathrm{~W}$ is added to the energy needed for itself.

The main cabinet containing the PLC will need a power supply of 230 VCA or a supply from 24 VDC source, depending on the infrastructure present on the skid where the cabinet shall be placed. In the case when a switched-mode power supply can be used for powering the PLC from the cabinet situated in safe area, the DC source in the WMAC would no longer be necessary. Relays have the role to isolate one voltage level from another.

If needed, the WMAC can be used in hazardous gas Zone 2 (Ex II 2G). The default data storage can be performed at minimum intervals of 1 sample/second, with the possibility to be customized depending on the needs. The rate with which the WSN sends data read to the PLC influences the battery lifetime. Considering the battery lifetime optimization for the wireless node, we seek to increase this rate to maximum possible, depending on the application requirements. The data reading frequency can be automatically increased by programming the PLC to do so when one or more parameters exceed certain thresholds.

The wireless node placed in the hazardous zone does not exceed the critical maximum power values defined by ATEX standard in force (Table 3), being within the IIC category. Ex ia is intrinsic protection, safe for Zones 0,1 and 2, which limits the energy (power, current, voltage) in the circuit of the electrical devices, so that a spark or a thermal effect cannot trigger any ignition of the potentially explosive atmosphere.

Table 3. Explosion groups and limiting energy and power

\begin{tabular}{|c|c|l|c|c|}
\hline Zone & $\begin{array}{c}\text { Explosion } \\
\text { Group }\end{array}$ & $\begin{array}{c}\text { Representative } \\
\text { gas }\end{array}$ & $\begin{array}{c}\text { Maximum } \\
\text { energy }\end{array}$ & $\begin{array}{c}\text { Maximum } \\
\text { power }\end{array}$ \\
\hline \multirow{2}{*}{ Zone 2} & I & Methane $\left(\mathrm{CH}_{4}\right)$ & $280 \mu \mathrm{J}$ & $\gtrsim 6 \mathrm{~W}$ \\
\cline { 2 - 5 } & IIA & Propane $\left(\mathrm{C}_{3} \mathrm{H}_{8}\right)$ & $260 \mu \mathrm{J}$ & $6 \mathrm{~W}$ \\
\hline Zone 1 & IIB & Ethylene $\left(\mathrm{C}_{2} \mathrm{H}_{4}\right)$ & $95 \mu \mathrm{J}$ & $4 \mathrm{~W}$ \\
\hline Zone 0 & IIC & $\begin{array}{l}\text { Hydrogen }\left(\mathrm{H}_{2}\right), \\
\text { Acetylene }\left(\mathrm{C}_{2} \mathrm{H}_{2}\right)\end{array}$ & $20 \mu \mathrm{J}$ & $2 \mathrm{~W}$ \\
\hline
\end{tabular}


If the necessity to monitor multiple machineries (e.g. compressor unit) arises, there can be added up to 32 wireless nodes, thus obtaining a maximum of 64 analogue inputs and 64 digital inputs. These figures are more than sufficient, considering that normally a compressor unit gathers around 15 analogue inputs, and the essential elements for a proactive monitoring are approximatively 1-2 vibrations, 1-2 temperatures and sometimes pressure, considered important and impacting the lifespan of the machine.

The node can be configured so that to be adaptable for the following types of sensors:

- 2 NPN (negative-positive-negative, NC - normally closed) or 2 PNP (positive-negativepositive, NO - normally open) digital inputs, and 2 unified current inputs (0-20 mA);

- 2 NPN or 2 PNP DI, and 2 AI in unified voltage (0-10 V);

- 3 thermocouples and 1 thermistor;

- 4 RTD (Resistance Temperature Detector) type PT100;

- 2 NPN and 2 bridges;

- 2 NPN plus bridge and thermistor.

This shows a great versatility, since the combinations listed above cover a very large range of sensors and transducers.

An inconvenient of this assembly is that it can only monitor the equipment, without being able to command it, through analogue and/or digital outputs. Moreover, when a data reading (acquisition) with maximum frequency of 1 sample/second is desired, the node's battery lifetime drops to less than one month. This, however, is not a drawback for a mobile cabinet that we would keep at headquarters and transport in different locations.

HolderPPS system (Fig. 3) was designed with the purpose of performing a continuous and dynamic monitoring of rotary bladed machines. Conceived as an element for proactive maintenance, this system enables the surveillance of the parameters and working conditions of the industrial processes, with the possibility of detecting the inchoate operation faults, which can be managed in time, before the occurrence of faults, which can cause downtimes and extra repair costs. The system makes use of an acquisition board programmed in LabView [11] and is currently being used intensively in monitoring gas turbines, engine starters, motors, compressors, blowers etc., installed both on test benches and remotely.

a)

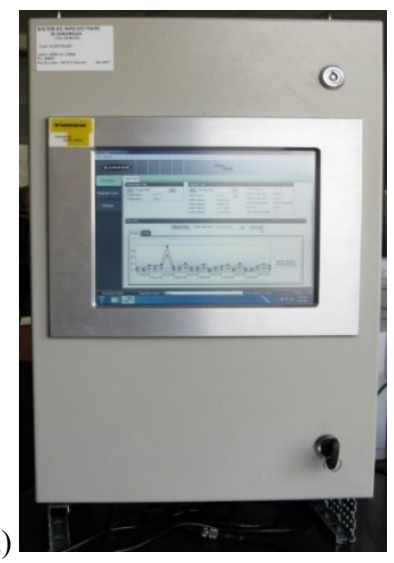

b)

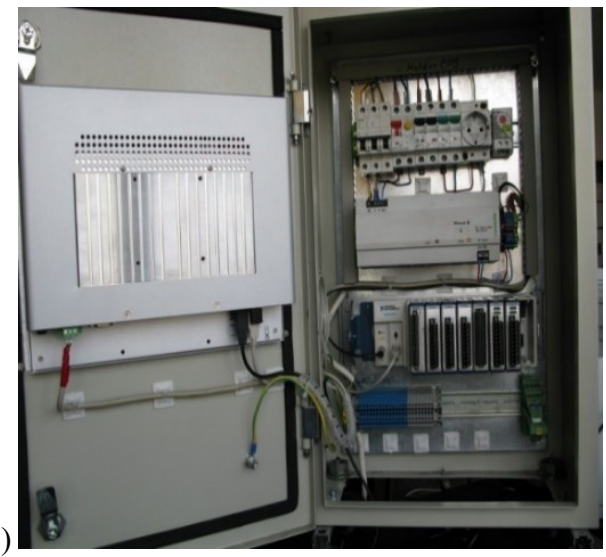

Fig. 3. Portable cabinet for non-hazardous zones a) Front door panel PC, b) Inside equipment [11]

\subsection{Components for wireless data transmission}

The main components used for testing the data transmission are presented in Fig. 4, and consist of a radio for hazardous areas [15], a gateway [16], a temperature sensor [17] and a device integrating both a wireless sensor node (WSN), as well as temperature and vibration 
sensors [18]. Both the radio and the gateway are certified ATEX. In the final solution to be implemented, all the sensors placed in hazardous areas shall also be in Ex construction.

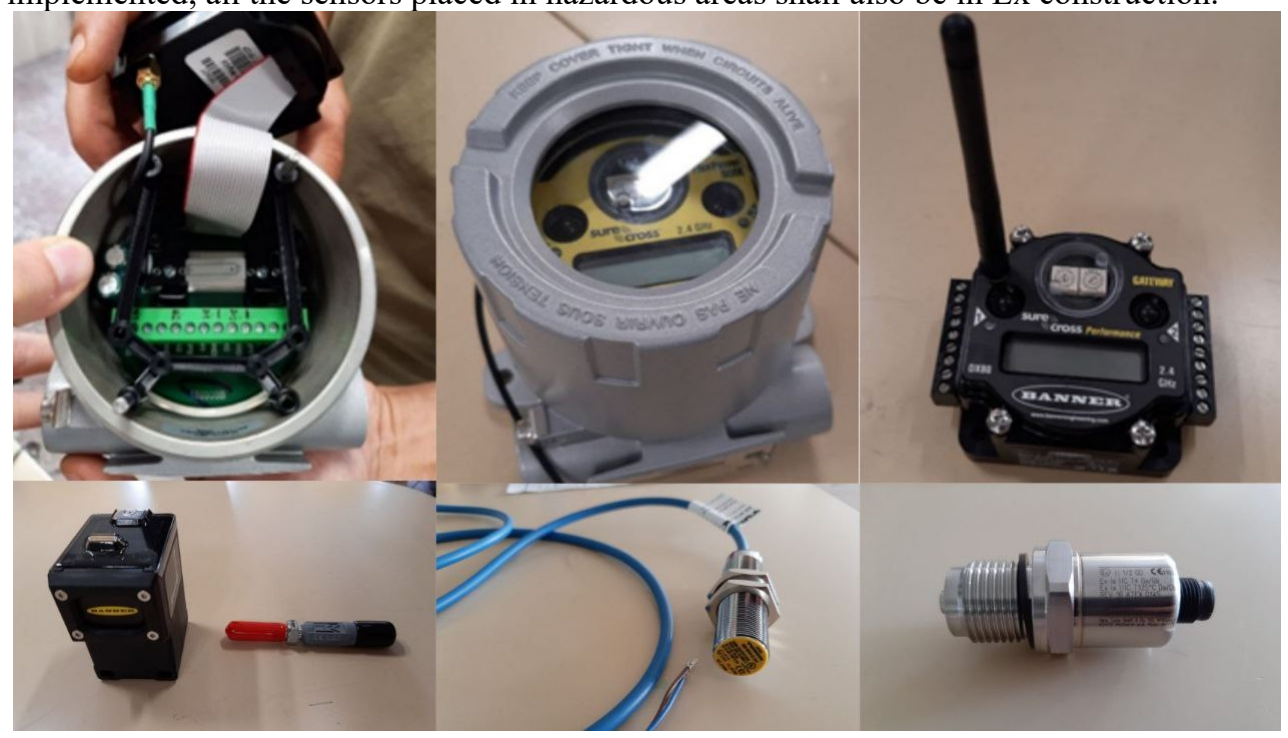

Fig. 4. Main components for prototype testing (from top left to bottom right: wireless node inside; wireless node housing; gateway; integrated vibration and temperature sensor; inductive distance sensor; pressure sensor.

We consider a battery powered wireless sensor node (WSN) combining both vibration and temperature sensor in a compact, industrial device that can communicate wireless with the gateway on a variety of machines. Its purpose is to analyse vibration and temperature data in order to identify and predict failures in rotating machinery [18], and thus being very suited for the application of predictive maintenance proposed in the paper herein.

Optionally, depending on the monitoring necessities, up to 50 sensors can be added (for example, pressure sensors, vibrations transducers, current transducers). The gateway is provided with two analogue inputs for receiving signals from usual ATEX pressure and temperature sensors. Table 4 below presents the devices in the field, with Ex protection.

Table 4. Equipment in the field with ATEX certification

\begin{tabular}{|c|c|c|c|}
\hline Component & ATEX certification & IP & Main specs \\
\hline Wireless node & $\begin{array}{l}\text { Ex II } 1 \text { GD Ex ia IIC } \\
\text { T4 }\end{array}$ & IP 68 & $\begin{array}{c}2.4 \mathrm{GHz} \text { Node } 65 \mathrm{~mW}, \\
\text { Input: } 2 \text { digital, } 2 \text { analogue, } \\
0-20 \mathrm{~mA}\end{array}$ \\
\hline Gateway & Ex II 3 G Ex nA II T4 & IP 67 & $\begin{array}{c}\text { Inputs: } 4 \text { digital, } 2 \text { analogue } \\
0-20 \mathrm{~mA} \text {; Outputs: } 4 \text { digital, } \\
2 \text { analogue } 0-20 \mathrm{~mA}, \\
2.4 \mathrm{GHz} \text { ISM Band }\end{array}$ \\
\hline Temperature sensor & Yes & IP 67 & $\begin{array}{c}0-20 \mathrm{~mA}, \\
0-100^{\circ} \mathrm{C} \text { domain }\end{array}$ \\
\hline Pressure sensor & Ex ia IIC T4 Ga/Gb & IP 67 & IN: $24 \mathrm{VDC}$, OUT: 4-20 mA \\
\hline $\begin{array}{c}\text { WSN with Integrated } \\
\text { Vibration \& Temperature } \\
\text { Sensor }\end{array}$ & Yes & IP 67 & $\begin{array}{c}\text { Sensor and Node, } 2.4 \mathrm{GHz} \\
\text { ISM Band }\end{array}$ \\
\hline Inductive distance sensor & Ex ia IIC T6 Ga & IP 67 & $\begin{array}{c}\text { Measuring range } 1 \ldots 5 \mathrm{~mm} \text {, } \\
\text { Output } 4-20 \mathrm{~mA}, 200 \mathrm{~Hz}\end{array}$ \\
\hline
\end{tabular}


The user configuration tool provided enables the easy linking of the I/O (inputs/outputs) ports within the wireless network, the graphical visualisation of the registered $\mathrm{I} / \mathrm{O}$ values, as well as setting the system communication parameters when a host system is not from the wireless network. A USB (Universal Serial Bus) to RS-485 adapter cable is used to connect a standalone DX80 gateway to computer. For DXM Controllers with internal DX80 radio, the computer is connected to the controller via either USB or Ethernet connection [15]. The gateway requires a PLC and a 24 VDC source, for optimum operation.

\section{Conclusions}

Communication cabling in industrial plants takes a considerable amount of time, effort and material handling. Replacing it with wireless instrumentation helps reduce human work and material costs, by eliminating expensive cables and most related wire infrastructure and work. This can easily compensate the downside of wireless equipment costs. Wireless transmission is also beneficial when considering the elimination of Joule heating in any electric cable carrying current. The proposed cabinet is also portable, easy to install and then switch to another plant. This is especially suitable when considering the maintenance of multiple plants in hazardous zones, with all the equipment inside having ATEX certifications. Previous experience has proven the unquestionable benefits of portable diagnosis cabinets, and an increasing need for multiple such systems.

We would like to thank mr. Valentin Rîpan, sales engineer at Turck Romania, for the collaboration, information, and technical assistance regarding product selection for the optimum configuration of the system proposed herein.

\section{References}

1. S. Grüner, M. Hoernicke, G. Fachinger, J. Grothoff, S. Cordes and A. Fay, Cross-Industry State of the Art Analysis of Modular Automation, Automation 2020: Shaping Automation for our Future 2375, pp. 899-914 (2020). DOI: $10.51202 / 9783181023754-899$.

2. Maarif and S. Suhartinah, Compact Portable Industrial Automation Kit for Vocational School and Industrial Training, IOP Conference Series: Materials Science and Engineering 384, p. 012011 (Bandung, Indonesia, 2018). DOI: 10.1088/1757-899X/384/1/012011.

3. L. Medina, R. Silva and Z. Soto, Industrial Engineering from the Vision of a Portable Automated Model, LACCEI 13 ${ }^{\text {th }}$ edition (Santo Domingo, Dominican Republic, 2015). DOI: 10.18687/LACCEI2015.1.1.072.

4. Y. Feng, C. He, J. Tan, H. Zheng and Y. Gao, Assessment of the Design Complexity of Modular Automated Assembly System, ICAMechS (Hanoi, Vietnam, 2020). DOI: 10.1109/ICAMechS49982.2020.9310121.

5. P. Alvarado-Velazco and V. Ayala-Ramirez, Methodology for modular automation system design, CONIELECOMP $21^{\text {st }}$ edition (San Andres Cholula, Mexico, 2011). DOI: 10.1109/CONIELECOMP.2011.5749338.

6. M. Părăian, S. Burian, M. Magyari and L. Moldovan, Aspects regarding explosion risk assessment, MATEC Web of Conferences 121, p. 11016 (2017). DOI: 10.1051/matecconf/201712111016.

7. ATEX Directive 2014/34/EU (2014).

8. I. Moldovan, M. Magyari. D. Fotău, M. Rad, D. Sălășan, C. Burian, M. Părăian, M. Darie, T. Csaszar, C. Colda, D. Grecea, A. Andriş, G. Pupăzan, N. Vătavu, A. Jurca, F. Păun, L. Lupu, D. Gabor, C. Popa, General requirements of explosion safety for the electric equipment situated in areas defined as hazardous, other than firedamp mines (Original title, RO: Cerinte generale de securitate la explozie pentru echipamente electrice amplasate $\hat{i n}$ arii definite ca periculoase, altele decât minele grizutoase), INSEMEX (2017).

9. R. STAHL, "Oil and Gas Explosion Hazards | Industries", R-stahl.com (2021). https://rstahl.com/en/global/industries/oil-and-gas-industry/. 
10. C. Vilcu, F. Niculescu, A. Mitru, C. Nechifor, C. Borzea and C. Cornea, "HolderCPS" - A new type data recorder system for proactive maintenance to rotary blade machines, ATEE $10^{\text {th }}$ edition (Bucharest, Romania, 2017). DOI: 10.1109/ATEE.2017.7905190.

11. F. Niculescu, C. Vîlcu and C. Borzea, Diagnosing of Rotary Blade Machines with the HolderPPS System, Journal Turbo, vol. IV, no. 2, pp. 8-13 (2017).

12. F. Niculescu, C. Vilcu, A. Gazdac and C. Borzea, Data Recorder System for Maintenance to Rotary Blade Machines - "HolderPPS”, Journal Turbo, vol. IV, no. 1, pp. 7-10 (2017).

13. R. STAHL, "Container Systems for Snubbing Units | Success Stories", R-stahl.com (2021). https://r-stahl.com/en/global/industries/success-stories/container-system-for-snubbing-unit/.

14. Atex Delvalle, "Pressurized Enclosures Ex P Peppex", Atexdelvalle.com (2021). https://www.atexdelvalle.com/en/pressurized-control-panel-enclosure-exp/pressurized-panelenclosure-cabinet-ex-p-peppex.

15. Banner, Sure Cross ${ }^{\circledR}$ DX99 Flexpower Node (Metalhousing) Datasheet, 142497 Rev. O, pdf (2016). https://info.bannerengineering.com/cs/groups/public/documents/literature/142497.pdf.

16. Banner, Sure Cross ${ }^{\circledR}$ Performance P2 Gateway Datasheet, 155861 Rev. H, pdf (2019). https://info.bannerengineering.com/cs/groups/public/documents/literature/155861.pdf.

17. Turck, Temperature Measurement in Fluids and Gases, pdf (2021). https://www.turck.de/attachment/d101933.pdf.

18. Banner, Sure Cross ${ }^{\circledR}$ Wireless Q45VA All-In-One Vibration and Temperature Node Datasheet, 205704 Rev. E https://info.bannerengineering.com/cs/groups/public/documents/literature/205704.pdf. 